\title{
Adubos verdes e adubação mineral nitrogenada em cobertura na cultura do trigo em plantio direto
}

\author{
Anísio da Silva Nunes ( $\left.{ }^{1 *}\right)$; Luiz Carlos Ferreira de Souza $\left({ }^{2}\right)$; Fábio Martins Mercante $\left({ }^{3}\right)$ \\ (1) Rua Hayel Bon Faker, 3710, 79806-000 Dourados (MS). \\ (2) Universidade Federal da Grande Dourados (UFGD), 79825-070 Dourados (MS). \\ (3) Embrapa Agropecuária Oeste, Caixa Postal 661, 78804-970 Dourados (MS). \\ (*) Autor correspondente: anisionunes@yahoo.com.br
}

Recebido: 19/abr./2009; Aceito: 9/dez./2010.

\begin{abstract}
Resumo
Objetivou-se neste trabalho avaliar o efeito do cultivo de adubos verdes, associados a doses de nitrogênio (N) em adubação de cobertura, no desempenho agronômico da cultura do trigo em sistema plantio direto. O experimento foi realizado em Dourados (MS), Brasil, em delineamento de blocos casualizados, com os tratamentos dispostos em esquema de parcelas subdivididas e quatro repetições. As parcelas foram constituídas pelos adubos verdes: ervilhaca peluda (Vicia villosa), crotalária (Crotalaria juncea), mucuna anã (Mucuna deeringiana), lablabe (Dolichus lablab) e um tratamento- testemunha, em pousio. Nas subparcelas foram testadas quatro doses de N em cobertura: 0 (zero), 45, 90 e $135 \mathrm{~kg} \mathrm{ha}^{-1}$, utilizando a uréia como fonte de N. Foram realizadas avaliações de massa seca das coberturas vegetais, teores de $\mathrm{N}$ nos tecidos da parte área dos adubos verdes e nas folhas de trigo, altura de plantas, número de perfilhos produtivos por planta, tamanho da espiga, número de grãos por espiga, massa de mil grãos, peso hectolitro e produtividade. Concluiu-se que maiores produtividades na cultura do trigo são obtidas quando é cultivado após crotalária e ervilhaca peluda e que a resposta do trigo à aplicação de $\mathrm{N}$ mineral em adubação de cobertura varia em função da cultura antecessora.
\end{abstract}

Palavras-chave: crotalária, ervilhaca peluda, lablabe, mucuna anã, Triticum spp.

\section{Green manures and mineral nitrogen topdressing fertilization of wheat crop under no-tillage}

\begin{abstract}
The objective of this work was to evaluate the effect of different green manures associated with levels of mineral nitrogen topdressing in the agronomic performance of wheat crop under no-tillage. The experiment was performed in Dourados, MS, Brazil, in randomized blocks experimental design, with treatments arranged in a split-plot scheme with four repetitions. The plots were constituted by hairy vetch (Vicia villosa), sunn hemp (Crotalaria juncea), velvet bean (Mucuna deeringiana), hyacinth bean (Dolichus lablab) and a treatment-control, in fallow. In the split-plot were tested four levels of mineral nitrogen top dressing: 0 (zero), 45, 90, and $135 \mathrm{~kg} \mathrm{ha}^{-1}$, using urea as source. Evaluations of cover crops shoot dry biomass, nitrogen contents in green manures shoot and in wheat leaves, plant height, number of productive tillers per plant, length of spike, number of grains per spike, one thousand-grains weight, hectoliter weight and yield were done. It was concluded that higher yields in wheat are obtained when it is grown after hairy vetch and sunn hemp and that the wheat yield response to mineral nitrogen top dressing application varies according to the preceding crop.
\end{abstract}

Key words: sunn hemp, hairy vetch, hyacinth bean, velvet bean, Triticum spp.

\section{INTRODUÇÃO}

A adubação verde é prática ainda pouco utilizada na cultura do trigo em regióes de clima tropical, embora proporcione benefícios do ponto de vista econômico e da preservaçáo dos recursos naturais. Muitos autores têm confirmado o aporte de nitrogênio $(\mathrm{N})$ proveniente do processo biológico promovido por bactérias diazotróficas e promotoras do crescimento vegetal, com o cultivo de leguminosas antecedendo as culturas econômicas (Amado et al., 2000; Santos et al., 2006; Silva et al., 2006). Entretanto, embora possa existir grande quantidade de $\mathrm{N}$ na parte aérea das espécies utilizadas como adubos verdes, a quantidade que será aproveitada pela cultura em sucessáo dependerá do sincronismo entre a decomposição da biomassa e a demanda da cultura (Aita et al., 2001).

$\mathrm{O} \mathrm{N}$ é um dos nutrientes absorvidos em maior quantidade pela cultura do trigo e sua carência pode ser fator limitante para seu desenvolvimento (TeIXeIrA FilHo et al., 2007). A disponibilidade desse nutriente no solo está vinculada, entre outros fatores, à relação 
carbono/nitrogênio $(\mathrm{C} / \mathrm{N})$ dos resíduos vegetais, principalmente no sistema plantio direto, onde permanecem na superfície do solo (ARAújo et al., 2005). No período compreendido entre o perfilhamento e o início da diferenciação do primórdio floral, por exemplo, a falta de $\mathrm{N}$ pode reduzir a formação de espiguetas (SANGOI et al., 2007).

Após a liberação inicial do $\mathrm{N}$ presente na fonte orgânica ou mineral, ele pode ser absorvido pelas plantas, perdido por lixiviação, volatilização, erosão e desnitrificação ou ainda permanecer no solo, predominantemente na forma orgânica (Bologna et al., 2006). Portanto, o conhecimento das interaçóes entre manejo dos adubos verdes, doses de fertilizantes minerais nitrogenados e exigências nutricionais da cultura em sucessão torna-se imprescindível ao desenvolvimento de estratégias de manejo que aumentem seu aproveitamento pelas culturas. ARAújo et al. (2005) avaliaram o efeito de adubos verdes e a aplicaçâo de uréia na recuperação de ${ }^{15} \mathrm{~N}$-uréia utilizado na cultura do trigo e obtiveram maiores recuperaçóes do ${ }^{15} \mathrm{~N}$-uréia pela cultura no manejo conjunto de uréia e crotalária, devido à maior disponibilidade de $\mathrm{N}$ no solo, que proporcionou o estreitamento da relaçáo $\mathrm{C} / \mathrm{N}$ do adubo verde e menor imobilização do nutriente do fertilizante na palha.

A utilização de adubos verdes em combinação com o fertilizante nitrogenado deve reduzir a dose desse último a ser aplicada na cultura do trigo, com possível reflexo no aumento da receita líquida por parte do agricultor (BRAZ, et al., 2006), além da obtenção de outros benefícios relacionados ao sistema de produção mais sustentável.

Os estudos sobre a influência dos resíduos culturais deixados na superfície do solo no rendimento da cultura do trigo em sucessão são relativamente recentes. As diversas espécies de plantas utilizadas como adubo verde proporcionam efeito residual variável, o que torna mais complexo a recomendação daquelas com maior potencialidade em relação ao aumento da produtividade para cada cultura econômica em sucessão.

Diversas leguminosas têm sido utilizadas como adubos verdes na região do cerrado brasileiro, entre elas o guandu [Cajanus cajan (L.) Millsp.], as crotalárias (Crotrolaria juncea L., Crotolaria ochroleuca G. Don., Crotalaria paulina Schrank e Crotolaria spectabilis Roth), as mucunas [Mucuna cinereum L., Mucuna deeringiana (Bort) Merr., Mucuna aterrima (Piper \& Tracy) Merr.], o feijāo-de-porco [Canavalia ensiformis (L.) DC], o feijãobravo-do-ceará (Canavalia brasiliensis Mart. ex Benth.) e as ervilhacas (Vicia sativa L., Vicia villosa Hoth, Vicia benghalensis L.). Todavia, a maioria dos trabalhos com adubos verdes tem sido realizada principalmente em rotaçáo com a cultura do milho, que possui necessidades e demandas muito distintas das exigidas pelo trigo.

Neste contexto, objetivou-se avaliar o efeito do cultivo de adubos verdes, associados a doses de $\mathrm{N}$ em adubação de cobertura, no desempenho agronômico da cultura do trigo em sistema plantio direto.

\section{MATERIAL E MÉTODOS}

O trabalho foi realizado em área experimental, localizada em Dourados (MS). O solo da área experimental foi classificado como Latossolo Vermelho distroférrico (EMbrapa, 2006), originalmente sob vegetação de cerrado. As amostras de solo, coletadas na profundidade de 0 a $0,2 \mathrm{~m}$, foram analisadas conforme Claessen (1997) e tiveram os seguintes resultados: $\mathrm{pH}\left(\mathrm{CaCl}_{2}\right)$ $=5,4$; matéria orgânica $(\mathrm{MO})=28 \mathrm{~g} \mathrm{dm}^{-3} ; \mathrm{P}($ resina $)=$ $9,0 \mathrm{mg} \mathrm{dm}{ }^{-3} ; \mathrm{Ca}=70,6 \mathrm{mmol} \mathrm{dm}^{-3} ; \mathrm{Mg}=25,3 \mathrm{mmol}$ $\mathrm{dm}^{-3} ; \mathrm{K}=2,5 \mathrm{mmol}_{\mathrm{c}} \mathrm{dm}^{-3} ; \mathrm{H}+\mathrm{Al}=45,0 \mathrm{mmol}_{\mathrm{c}} \mathrm{dm}^{-3}$; CTC $=143,4 \mathrm{mmol}_{c} \mathrm{dm}^{-3}$ e saturação por bases $(\mathrm{V})=$ $68 \%$. O histórico dos últimos cinco anos da área experimental, cultivada em sistema plantio direto, consistiu na rotação das seguintes culturas: soja, crotalária, milho (verão), girassol, soja e milho (safrinha).

O delineamento experimental utilizado foi o de blocos casualizados, com os tratamentos dispostos em um esquema de parcelas subdivididas, com quatro repetiçóes. As parcelas, com $6 \mathrm{~m}$ de largura e $12 \mathrm{~m}$ de comprimento $\left(72 \mathrm{~m}^{2}\right)$, foram constituídas pelos adubos verdes cultivados antes da implantação da cultura do trigo: ervilhaca peluda (Vicia villosa Hoth), crotalária (Crotalaria juncea L.), mucuna anã [Mucuna deeringiana (Bort) Merr.] e lablabe (Dolichus lablab L.), além de um tratamento testemunha, sem o cultivo de adubo verde (em pousio). Nas subparcelas, com $6 \times 3 \mathrm{~m}\left(18 \mathrm{~m}^{2}\right)$, foram testadas quatro doses de $\mathrm{N}$ em adubação de cobertura na cultura do trigo: $0,45,90$ e $135 \mathrm{~kg} \mathrm{ha}^{-1}$ de $\mathrm{N}$.

Os adubos verdes foram semeados mecanicamente sobre a resteva de milho da safra anterior, na segunda quinzena de março e manejados aos 64 dias após a semeadura, com a aplicação do herbicida glyphosate na dose de 2,4 $\mathrm{L} \mathrm{ha}^{-1}$. As plantas de crotalária foram acamadas com o uso de um rolo-faca antes da aplicação do herbicida.

Determinou-se a produção de massa seca e os teores de nutrientes na parte área dos adubos verdes utilizandose quadro de $0,25 \mathrm{~m}^{2}$ lançado aleatoriamente nas parcelas, com oito amostras por tratamento. As plantas foram cortadas rente ao solo, lavadas e secas em estufa com circulação forçada de ar a $65^{\circ} \mathrm{C}$, até massa constante. Após a secagem, o material amostrado foi moído para determinaçáo dos teores de $\mathrm{N}$ na parte aérea dos adubos verdes, pelo método de Kjeldahl (Malavolta et al., 1997).

A vegetação espontânea presente nas parcelas em pousio era composta principalmente por trapoeraba (Commelina benghalensis L.), amendoim bravo (Euphorbia heterophylla L.), caruru de mancha (Amaranthus viridis L.) e capim braquiária (Brachiaria decumbens Stapf).

Antes da semeadura do trigo, aplicou-se na área experimental o herbicida paraquat na dose de $1,33 \mathrm{~L} \mathrm{ha}^{-1}$ para o controle das plantas daninhas remanescentes. $\mathrm{O}$ trigo foi semeado mecanicamente, na segunda quinzena de maio, com adubação de $60 \mathrm{~kg} \mathrm{ha}^{-1}$ de $_{2} \mathrm{O}_{5}$ e $60 \mathrm{~kg}$ 
ha $^{-1}$ de $\mathrm{K}_{2} \mathrm{O}$. A cultivar utilizada foi a BR 18, com 60 sementes por metro e espaçamento entrelinhas de $0,17 \mathrm{~m}$. A adubaçáo nitrogenada de cobertura ocorreu aos trinta dias após a semeadura do trigo, quando estava na fase de perfilhamento. A aplicação das diferentes doses estudadas foi realizada manualmente, próxima à linha de semeadura e na superfície do solo, tendo a uréia ( $45 \%$ de $\mathrm{N})$, como fonte de $\mathrm{N}$, por ser o fertilizante utilizado em cobertura pela maioria dos triticultores brasileiros. A maior dose foi parcelada em duas aplicaçôes, e a segunda aplicação ocorreu uma semana após a primeira.

Para o controle complementar de plantas daninhas na cultura do trigo aplicou-se o herbicida metsulfuron-metil, na dose de $4 \mathrm{~g} \mathrm{ha}^{-1}$, aos 20 dias após a semeadura. Aos 28 e 35 dias após a semeadura foram aplicados o fungicida tebuconazol + trifloxistrobina e o inseticida imidacloprid + betacyfluthrin.

A amostragem das folhas de trigo foi realizada no início do espigamento, sendo coletadas 30 folhas-bandeira por subparcela, as quais foram secas em estufa sob circulação forçada de ar a $65^{\circ} \mathrm{C}$, até massa constante. Após a secagem, as folhas foram moídas e submetidas à determinação dos teores de $\mathrm{N}$ como descrito anteriormente.

$\mathrm{Na}$ colheita, determinou-se a altura das plantas de trigo, pela medida compreendida entre a superfície do solo e a inserção da folha bandeira, e o número de perfilhos produtivos por planta, com a amostragem de dez plantas por subparcela. No mesmo dia foram coletadas dez espigas por subparcela para determinação do tamanho de espigas e número de grãos por espiga. As plantas presentes nas sete linhas centrais da área útil da parcela foram cortadas manualmente e, posteriormente, trilhadas. Os grãos, após beneficiamento, tiveram a umidade corrigida para 13\% para as avaliaçóes de massa de mil grãos, peso hectolitro e produtividade.

Os dados foram submetidos ao teste de normalidade de Lilliefors e ao teste $\mathrm{F}$ a 5\% de probabilidade. Os efeitos dos adubos verdes foram avaliados pela comparação das médias dos tratamentos pelo teste de Tukey a $5 \%$ de probabilidade, enquanto o efeito das doses de $\mathrm{N}$ em cobertura na cultura do trigo foi analisado por meio de análise de regressão. Quando o teste $\mathrm{F}$ foi significativo para a interação adubo verde $\mathrm{x}$ doses de $\mathrm{N}$, avaliaram os resultados por meio do desdobramento da interação. O software utilizado nas análises estatísticas foi o Assistat (Silva e Azevedo, 2002).

\section{RESULTADOS E DISCUSSÃO}

Dentre os adubos verdes estudados, a crotalária produziu a maior quantidade de massa seca aos 64 dias após a semeadura, enquanto a ervilhaca peluda e a mucuna, as menores quantidades (Tabela 1). A baixa produção de massa seca da ervilhaca peluda pode ser atribuída ao seu crescimento inicial lento e ao intervalo restrito de tempo entre a colheita da safra de verão e a semeadura do trigo, circunstância que impossibilitou o pleno desenvolvimento vegetativo do adubo verde. Melhores resultados em produção de massa seca pela ervilhaca peluda foram avaliados por Martins e Rosa Júnior (2005) e SiLva et al. (2006), que estudaram o cultivo de ervilhaca peluda como adubo verde na cultura do milho em Dourados (MS) e relataram quantidades de massa seca para essa leguminosa acima de $3.000 \mathrm{~kg} \mathrm{ha}^{-1}$, aos 113 e 153 dias após a semeadura respectivamente. A produçáo de massa seca pela mucuna anã foi prejudicada pelo baixo estande da cultura, que ocorreu devido às dificuldades na operação de semeadura.

A maior quantidade de material vegetal proporcionou à crotalária os maiores teores de nitrogênio acumulado, em kg ha ${ }^{-1}$. Observou-se também nas plantas de crotalária elevada produção de massa seca aliada a bons teores de $\mathrm{N}$ na parte aérea, enquanto o lablabe, embora tenha apresentado teor de $\mathrm{N}$ semelhante ao verificado para a crotalária, produziu cerca de $50 \%$ menos massa seca em relação a esta última, resultando em menor $\mathrm{N}$ acumulado (Tabela 1). Independentemente da espécie de adubo verde utilizada, os valores mensurados nos adubos verdes foram superiores aos observados no tratamento em pousio.

Tabela 1. Massa seca (MS), teor de nitrogênio e quantidade acumulada deste nutriente ( $\mathrm{N}$ acumulado) na parte área das coberturas vegetais, e altura de plantas de trigo. Dourados (MS), 2008

\begin{tabular}{|c|c|c|c|c|}
\hline \multirow{2}{*}{ Tratamentos } & MS & Teor de $\mathbf{N}$ & $\mathrm{N}$ acumulado & Altura \\
\hline & $\mathbf{k g ~ h a}^{-1}$ & $\mathbf{g ~ k g}^{-1}$ & kg ha-1 & $\mathrm{cm}$ \\
\hline Ervilhaca & $1.480 \mathrm{c}$ & $42,2 \mathrm{a}$ & $62,5 \mathrm{~b}$ & $50,3 \mathrm{a}$ \\
\hline Crotalária & $5.620 \mathrm{a}$ & $32,6 \mathrm{~b}$ & $183,2 \mathrm{a}$ & $48,9 a$ \\
\hline Labe labe & $2.500 \mathrm{~b}$ & $27,8 \mathrm{~b}$ & $69,5 \mathrm{~b}$ & $48,0 \mathrm{a}$ \\
\hline Mucuna & $1.520 \mathrm{c}$ & $28,9 b$ & $43,9 \mathrm{c}$ & $46,7 \mathrm{a}$ \\
\hline Pousio & $140 \mathrm{~d}$ & $13,0 \mathrm{c}$ & $1,8 \mathrm{~d}$ & $46,6 \mathrm{a}$ \\
\hline D.M.S. & 872 & 4,9 & 12,4 & 4,5 \\
\hline C.V. (\%) & 12,2 & 6,8 & 12,3 & 8,2 \\
\hline
\end{tabular}

Médias seguidas por letras diferentes em uma mesma coluna diferem entre si pelo teste de Tukey a $5 \%$ de probabilidade. 
Os teores de $\mathrm{N}$ nas folhas de trigo no início do espigamento (Tabela 2) estão adequados segundo os padrôes nutricionais preconizados por RAIJ et al. (1997), considerado entre 20 e $34 \mathrm{~g} \mathrm{~kg}^{-1}$, exceto no tratamento sem o cultivo de adubos verdes (pousio) e sem adubação mineral nitrogenada em cobertura. As plantas de trigo cultivadas após os adubos verdes estavam com maiores teores de $\mathrm{N}$ nas folhas do que as semeadas após o tratamento-testemunha em pousio, nas doses testadas (Tabela 2). Estes resultados corroboram com os dados da tabela 1 , em que o tratamento pousio foi menos efetivo na introdução de $\mathrm{N}$ a partir da superfície do solo, via massa de resíduo vegetal. Os elevados teores de $\mathrm{N}$ nas plantas de trigo cultivado após a ervilhaca peluda, mesmo com menor quantidade de massa seca produzida, estão relacionados à rápida decomposição e mineralização de seus tecidos vegetais, que são menos lignificados e possuem baixa relação C/N (SILva et al., 2006).

O cultivo de adubos verdes não influenciou significativamente a altura das plantas de trigo (Tabela 1), enquanto a maior altura de plantas $(50,7 \mathrm{~cm})$ foi calculada na dose de 115,9 $\mathrm{kg} \mathrm{ha}^{-1}$ de N (Figura 1a). Resultados diferentes foram observadoas por TeiXeira Filho et al. (2007) que, estudando cinco doses de uréia em adubação de cobertura, constataram que não houve efeito das doses de uréia sobre a altura de plantas, possivelmente devido

Tabela 2. Teores de nitrogênio nas folhas de trigo, em função das culturas antecessoras e das doses de nitrogênio mineral em cobertura. Dourados (MS), 2008

\begin{tabular}{lcccc} 
& \multicolumn{5}{c}{ Doses de N } \\
\cline { 2 - 5 } Tratamentos & $\mathbf{0}$ & $\mathbf{4 5}$ & $\mathbf{9 0}$ & $\mathbf{1 3 5}$ \\
\cline { 2 - 5 } & \multicolumn{5}{c}{$\mathbf{k g ~ h a}^{-1}$} \\
Ervilhaca & $32,4 \mathrm{a}$ & $35,3 \mathrm{a}$ & $38,1 \mathrm{a}$ & $34,8 \mathrm{a}$ \\
\hline Crotalária & $24,2 \mathrm{~b}$ & $34,9 \mathrm{a}$ & $36,5 \mathrm{ab}$ & $30,6 \mathrm{a}$ \\
\hline Labe labe & $31,3 \mathrm{a}$ & $34,5 \mathrm{a}$ & $35,7 \mathrm{ab}$ & $32,3 \mathrm{a}$ \\
\hline Mucuna & $21,7 \mathrm{~b}$ & $31,3 \mathrm{a}$ & $31,3 \mathrm{~b}$ & $29,5 \mathrm{a}$ \\
\hline Pousio & $16,1 \mathrm{c}$ & $22,7 \mathrm{~b}$ & $25,7 \mathrm{c}$ & $24,0 \mathrm{~b}$
\end{tabular}

Médias seguidas por letras diferentes em uma mesma coluna diferem entre si pelo teste de Tukey a 5\% de probabilidade. D.M.S. = 5,4 e C.V. $(\%)=9,2$. à aplicação de $\mathrm{N}$-mineral na semeadura e à adubação de cobertura em um estágio mais tardio da cultura, aos 40 dias após a emergência.

Observou-se no experimento um baixo número de perfilhos produtivos por planta e que o perfilhamento das plantas de trigo cultivadas após a ervilhaca peluda foi estatisticamente superior ao das plantas cultivadas após a mucuna anã ou ao pousio (Tabela 3). O número de perfilhos produtivos por planta está diretamente associado à produção de espigas por unidade de área e, consequentemente, com a produtividade (Tabela 5). Um dos motivos da baixa produtividade média das lavouras de trigo no Brasil é a pequena participação dos perfilhos na formação do rendimento final (Almeida et al., 2002). O maior número de perfilhos produtivos por planta $(2,2)$ pode ser obtido na dose de $88,9 \mathrm{~kg}$ ha $^{-1}$ (Figura 1b). ZAGONEL et al. (2002), ao avaliar quatro doses de $\mathrm{N}\left(0,45,90\right.$ e $\left.135 \mathrm{~kg} \mathrm{ha}^{-1}\right)$ em diferentes populaçôes de trigo, também observaram o aumento do número de perfilhos produtivos por planta com o acréscimo de $\mathrm{N}$ em cobertura, entretanto, até a dose de $105 \mathrm{~kg} \mathrm{ha}^{-1}, 20 \%$ maior do que a obtida no presente trabalho.

As maiores espigas de trigo foram observadas nos tratamentos com ervilhaca peluda, crotalária e lablabe (Tabela 3). Segundo SANGor et al. (2007), a adubação nitrogenada pode refletir em aumento no tamanho das espigas de trigo, desde que esta prática agrícola ocorra até o estágio de emissão do segundo perfilho, como realizado neste experimento. $\mathrm{Na}$ análise de regressão para tamanho médio de espiga o maior tamanho de espiga $(7,7 \mathrm{~cm})$ foi calculado na dose de $110 \mathrm{~kg} \mathrm{ha}^{-1}$ de $\mathrm{N}$ na adubação de cobertura (Figura 1c).

O cultivo de adubos verdes antecedendo a cultura do trigo resultou em maior número de grãos por espiga de trigo (Tabela 3), se comparado ao pousio, devido à melhor nutriçáo das plantas de trigo (Tabela 2). Independentemente da cobertura vegetal, o maior número de grãos por espiga $(31,4)$ foi obtido com a adição de $100 \mathrm{~kg} \mathrm{ha}^{-1}$ de N (Figura 2a). Estes resultados corroboram os constatados por Cazetta et al. (2008), que avaliaram o efeito de doses de $\mathrm{N}$ em cobertura na qualidade industrial de

Tabela 3. Número de perfilhos produtivos, tamanho de espiga, número de grãos por espiga, massa de mil grãos e peso hectolitro ( $\mathrm{PH})$, em função das culturas antecessoras. Dourados (MS), 2008

\begin{tabular}{|c|c|c|c|c|c|}
\hline Tuntomonto & Perfilhos & Tamanho de espiga & Grãos por espiga & Massa de mil grãos & PH \\
\hline Irdadatitos & $n .^{\circ}$ & $\mathrm{cm}$ & n. ${ }^{\circ}$ & g & $\mathbf{k g ~ h L ^ { - 1 }}$ \\
\hline Ervilhaca & $2,2 \mathrm{a}$ & $7,8 \mathrm{a}$ & $32,7 \mathrm{a}$ & $36,6 \mathrm{a}$ & $78,8 \mathrm{a}$ \\
\hline Crotalária & $2,0 a b$ & $7,4 a b$ & $30,8 \mathrm{ab}$ & $36,1 \mathrm{a}$ & 77,9 a \\
\hline Labe labe & $1,9 a b$ & $7,2 \mathrm{ab}$ & $30,3 \mathrm{~b}$ & $35,9 \mathrm{a}$ & $76,2 \mathrm{~b}$ \\
\hline Mucuna & $1,6 b$ & $7,0 \mathrm{bc}$ & $29,8 \mathrm{~b}$ & $34,3 \mathrm{~b}$ & $75,8 \mathrm{~b}$ \\
\hline Pousio & $1,5 b$ & $6,4 c$ & $24,2 \mathrm{c}$ & $34,1 \mathrm{~b}$ & $74,8 \mathrm{~b}$ \\
\hline D.M.S & 0,5 & 0,7 & 2,1 & 1,2 & 1,7 \\
\hline C.V. (\%) & 24,5 & 8,7 & 6,4 & 3,1 & 2,5 \\
\hline
\end{tabular}

Médias seguidas por letras diferentes em uma mesma coluna diferem entre si pelo teste de Tukey a 5\% de probabilidade. 
cultivares de trigo em sistema plantio direto, e observaram aumento do número de grãos por espiga com o aumento das doses de N.

Os valores de massa de mil gráos nas plantas de trigo cultivadas após ervilhaca peluda, crotalária e lablabe foram superiores aos observados no trigo após o cultivo de mucuna anã e após o pousio (Tabela 3). Em relação às doses de $\mathrm{N}$ em cobertura, a maior massa de mil grãos (36,9 g por mil gráos) pode ser obtida na dose de 87,5 $\mathrm{kg} \mathrm{ha}^{-1}$ de N (Figura 2b). Estes resultados corroboram os
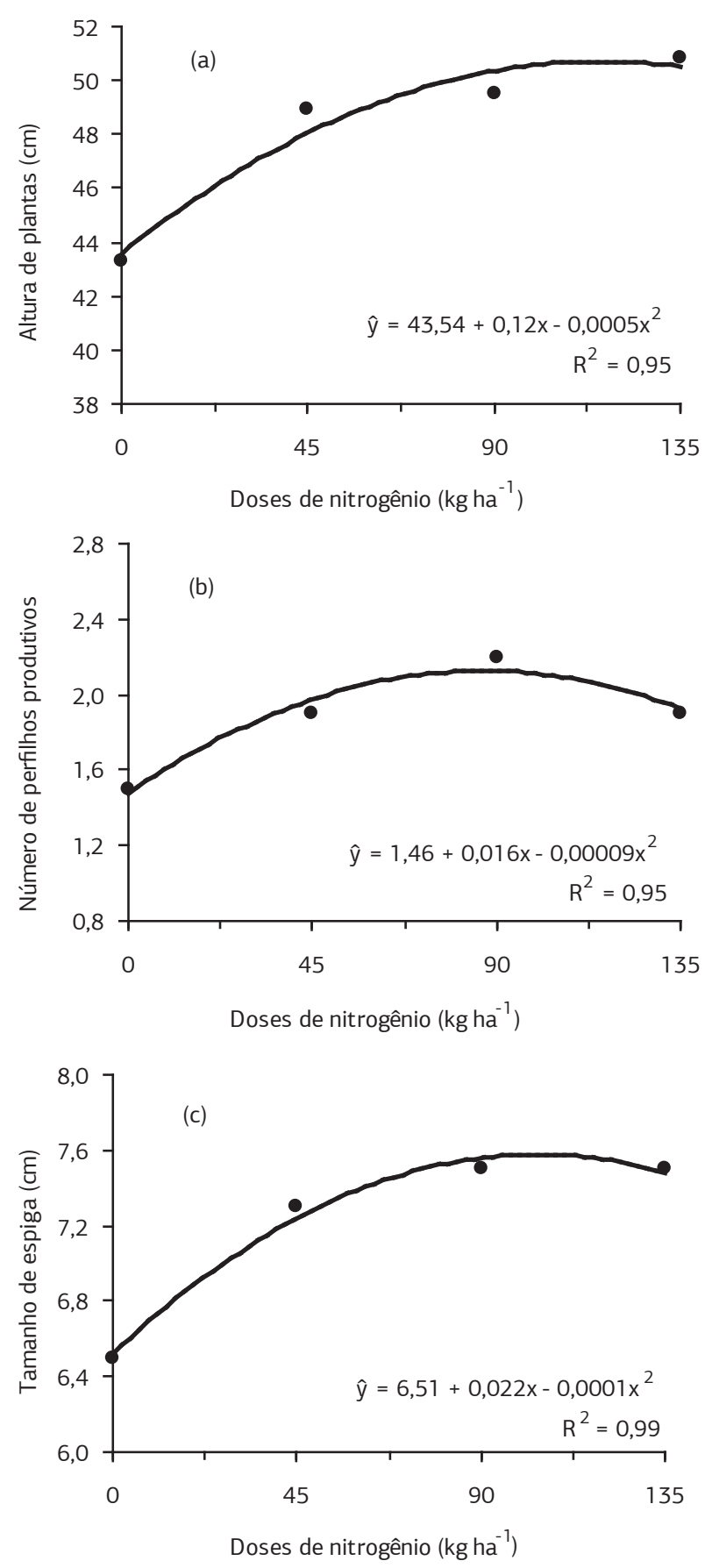

Figura 1. Altura das plantas de trigo (a), número de perfilhos produtivos por planta (b) e tamanho de espiga (c), em função das doses de nitrogênio em cobertura. Dourados (MS), 2008. obtidos por Teixeira Filho et al. (2007), que avaliaram as doses de $0,30,60,90$ e $120 \mathrm{~kg} \mathrm{ha}^{-1}$ de N, na forma de uréia, na cultura do trigo, e verificaram efeito significativo de diferentes doses de $\mathrm{N}$ em cobertura na massa de cem grãos do trigo, e diferem dos resultados relatados por BrAz et al. (2006), entretanto, não observaram diferença estatística na massa de mil grãos do trigo cultivado em sistema plantio direto em sucessão a braquiária, guandu, milheto, mombaça, sorgo granífero e estilosantes. Segundo Oкuунма et al. (2004), a massa de grãos possui grande
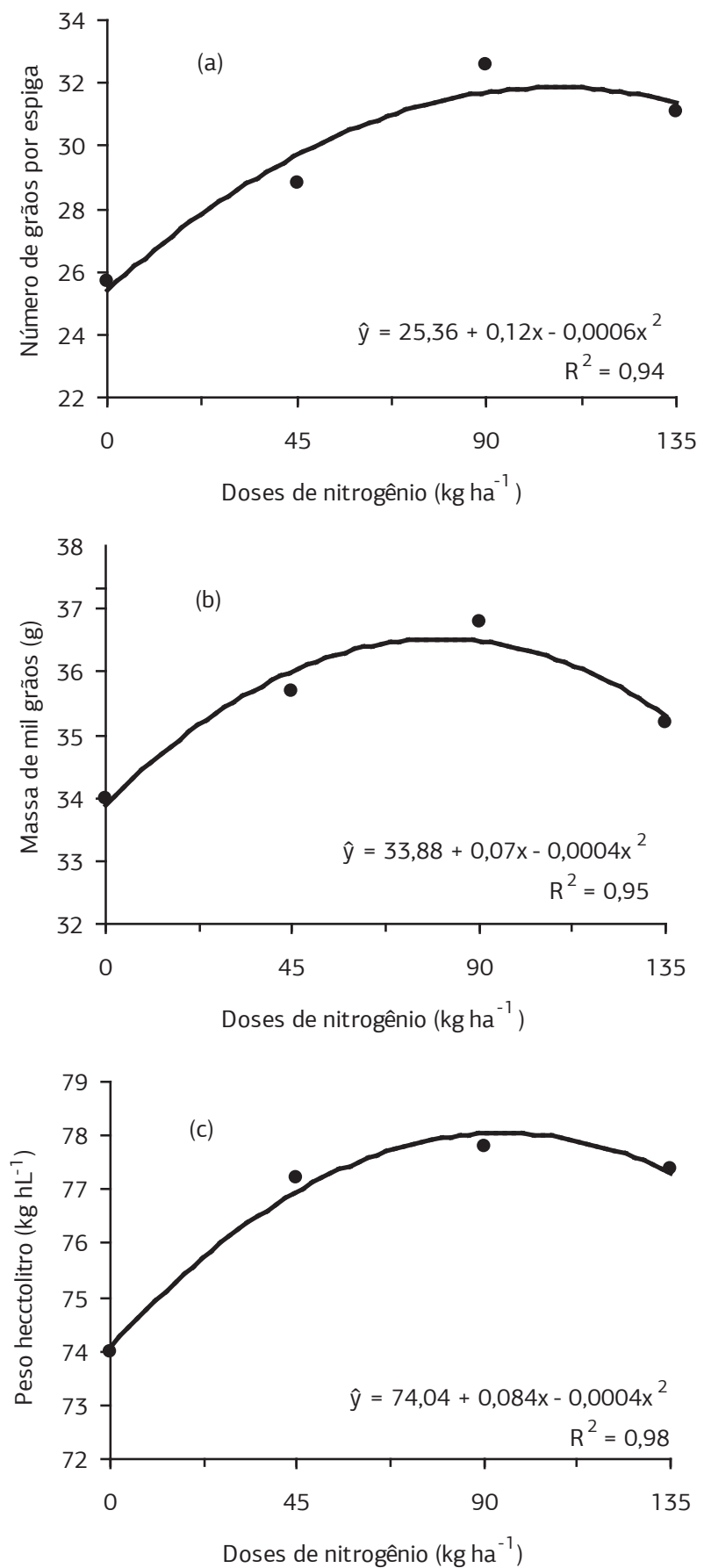

Figura 2. Número de grãos por espiga (a), massa de mil grãos (b) e peso hectolitro (c), em funçáo das doses de nitrogênio em cobertura. Dourados (MS), 2008. 


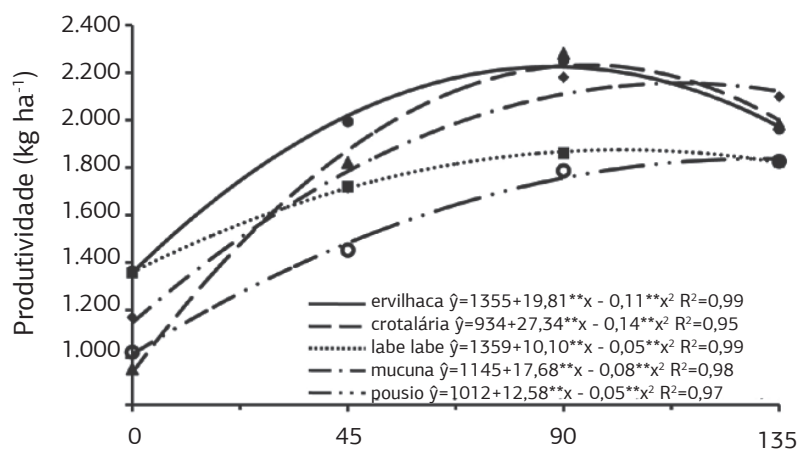

Figura 3. Produtividade da cultura do trigo $\left(\mathrm{kg} \mathrm{ha}^{-1}\right)$, em função dos adubos verdes e das doses de nitrogênio em cobertura. Dourados (MS), 2008. (** significativo a $1 \%$ de probabilidade).
Tabela 4. Produtividade da cultura do trigo $\left(\mathrm{kg} \mathrm{ha}^{-1}\right)$, em função das culturas antecessoras e das doses de nitrogênio em cobertura. Dourados (MS), 2008

\begin{tabular}{lcccc} 
& \multicolumn{4}{c}{ Doses de N } \\
\cline { 2 - 5 } Tratamentos & $\mathbf{0}$ & $\mathbf{4 5}$ & $\mathbf{9 0}$ & $\mathbf{1 3 5}$ \\
\cline { 2 - 5 } & \multicolumn{4}{c}{$\mathbf{k g ~ h a}^{-1}$} \\
Ervilhaca & $1.364 \mathrm{a}$ & $1.993 \mathrm{a}$ & $2.249 \mathrm{a}$ & $2.098 \mathrm{a}$ \\
\hline Crotalária & $952 \mathrm{~b}$ & $1.821 \mathrm{ab}$ & $2.281 \mathrm{a}$ & $1.982 \mathrm{a}$ \\
\hline Labe labe & $1.357 \mathrm{a}$ & $1.719 \mathrm{ab}$ & $2.180 \mathrm{a}$ & $1.963 \mathrm{a}$ \\
\hline Mucuna & $1.169 \mathrm{ab}$ & $1.714 \mathrm{~b}$ & $1.861 \mathrm{~b}$ & $1.826 \mathrm{a}$ \\
\hline Pousio & $1.023 \mathrm{~b}$ & $1.435 \mathrm{c}$ & $1.786 \mathrm{~b}$ & $1.823 \mathrm{a}$
\end{tabular}

Médias seguidas por letras diferentes em uma mesma coluna diferem entre si pelo teste de Tukey a 5\% de probabilidade. D.M.S. = 276 e C.V. $(\%)=8,9$.

Tabela 5. Coeficientes de correlação simples entre as variáveis: nitrogênio foliar (NF), altura de plantas (AP), número de perfilhos produtivos por planta $(\mathrm{PP})$, tamanho da espiga (TE), número de grãos por espiga $(\mathrm{GE})$, massa de mil grãos (MG), produtividade (PROD) e peso hectolitro (PH). Dourados (MS), 2008

\begin{tabular}{|c|c|c|c|c|c|c|c|c|}
\hline & NF & PP & AP & TE & GE & MG & PH & PROD \\
\hline $\mathrm{NF}$ & 1 & $0,46^{* *}$ & $0,13^{\text {ns }}$ & $0,55^{* *}$ & $0,63^{* *}$ & $0,50^{* *}$ & $0,56^{* *}$ & $0,60^{* *}$ \\
\hline PP & & 1 & $0,32^{* *}$ & $0,33^{* *}$ & $0,42^{* *}$ & $0,51^{* *}$ & $0,21^{\mathrm{ns}}$ & $0,51^{* *}$ \\
\hline AP & & & 1 & $0,16^{\mathrm{ns}}$ & $0,18^{\mathrm{ns}}$ & $0,20^{\text {ns }}$ & $0,23^{*}$ & $0,53^{* *}$ \\
\hline TE & & & & 1 & $0,56^{* *}$ & $0,42^{* *}$ & $0,50^{* *}$ & $0,63^{* *}$ \\
\hline GE & & & & & 1 & $0,51^{* *}$ & $0,57^{* *}$ & $0,71^{* *}$ \\
\hline MG & & & & & & 1 & $0,45^{* *}$ & $0,42^{* *}$ \\
\hline $\mathrm{PH}$ & & & & & & & 1 & $0,53^{* *}$ \\
\hline PROD & & & & & & & & 1 \\
\hline
\end{tabular}

** significativo a $1 \%$ de probabilidade; * significativo a $5 \%$ de probabilidade; ${ }^{\text {ns }}$ não significativo.

influência na produtividade do trigo em condiçóes que resultam em baixo número de perfilhos por unidade de área, como neste trabalho (Tabela 5).

Os maiores valores de peso hectolitro do trigo foram determinados quando foi cultivado após a ervilhaca peluda e crotalária (Tabela 3). O ajuste da equação quadrática para as doses de $\mathrm{N}$ em cobertura (Figura 2c) permite determinar o ponto de máxima resposta $\left(78,5 \mathrm{~kg} \mathrm{hL}^{-1}\right)$ na dose de $105 \mathrm{~kg} \mathrm{ha}^{-1} \mathrm{de} \mathrm{N}$. O peso hectolitro é utilizado na classificaçáo e comercialização do trigo, estando relacionado à uniformidade, forma, densidade e ao tamanho do grão, ao conteúdo de matérias estranhas e aos grãos quebrados da amostra. Para a classificação e comercialização do trigo como tipo 1, o valor mínimo para o peso hectolitro é de $78 \mathrm{~kg} \mathrm{hL}^{-1}$, obtido apenas nas parcelas cultivadas após a ervilhaca e a crotalária.

A produtividade do trigo foi influenciada por ambos os fatores estudados (adubos verdes e doses de $\mathrm{N}$ em cobertura), com interação significativa entre eles (Tabela 4). O cultivo de ervilhaca peluda, crotalária e lablabe antecedendo a cultura do trigo resultou em maiores produtividades, na maioria das doses de $\mathrm{N}$ testadas. Estes resultados corroboram os relatados por Braz et al. (2006), que observam em que para mesma dose de $\mathrm{N}$, a produtividade do trigo é maior quando é cultivado após leguminosas.
O maior acréscimo de produtividade ocasionado pela aplicação de nitrogênio mineral foi observado nos tratamentos com crotalária, assim como a maior produtividade do experimento $\left(2.269 \mathrm{~kg} \mathrm{ha}^{-1}\right)$, estimada na dose de $95 \mathrm{~kg} \mathrm{ha}^{-1}$ de nitrogênio em adubação de cobertura (Figura 3). Dentre as avaliaçóes realizadas, o teor de nitrogênio nas folhas de trigo e o número de grãos por espiga são os melhores indicadores de como a adubação nitrogenada de cobertura e o uso de adubos verdes interferiram significativamente na obtenção de maior produtividade na cultura do trigo (Tabela 5).

\section{CONCLUSÃO}

Maiores produtividades na cultura do trigo são obtidas quando é cultivado após crotalária e ervilhaca peluda. A resposta do trigo à aplicaçáo de $\mathrm{N}$ mineral em adubaçáo de cobertura varia em função da cultura antecessora.

\section{AGRADECIMENTOS}

À Fundação de Apoio e de Desenvolvimento do Ensino, Ciência e Tecnologia do Estado de Mato Grosso do 
Sul - FUNDECT, pela concessão da bolsa de estudos ao primeiro autor e pelo apoio financeiro para o desenvolvimento do projeto.

\section{REFERÊNCIAS}

AITA, C.; BASSO, C.J.; CERETA, C.A.; GONÇALVES, C.N.; DA ROS, C.O. Plantas de cobertura de solo como fonte de nitrogênio ao milho. Revista Brasileira de Ciência do Solo, v.25, p.157-165, 2001.

ALMEIDA, M.L.; SANGOI, L.; TRENTIN, P.S.; GÁLIO, J. Cultivares de trigo respondem diferentemente à qualidade da luz quanto à emissão de afilhos e acumulação de massa seca. Ciência Rural, v.32, p.377-383, 2002.

AMADO, T.J.C.; MIELNICZUK, J.; FERNANDES, S.B.V. Leguminosas e adubação mineral como fontes de nitrogênio para o milho em sistemas de preparo do solo. Revista Brasileira de Ciência do Solo, v.24, p.179-189, 2000.

ARAÚJO, A.F.; TEIXEIRA, G.M.; CAMPOS, A.X.; SILVA, F.C.; AMBROSANO, E.J.; TRIVELIN, P.C.O. Utilização de nitrogênio pelo trigo cultivado em solo fertilizado com adubo verde (Crotalaria juncea) e/ou uréia. Ciência Rural, v.35, p.284-289, 2005.

BOLOGNA, I.R.; FARONI, C.E.; LANGE, A.; TRIVELIN, P.C. Perda de nitrogênio pela parte aérea de plantas de trigo. Ciência Rural, v.36, p.1106-1111, 2006.

BRAZ, A.J.B.P.; SILVEIRA, P.M.; KLIEMANN, H.J.; ZIMMERMANN, F.J.P. Adubação nitrogenada em cobertura na cultura do trigo em sistema plantio direto após diferentes culturas. Ciência e Agrotecnologia, v.30, p.193-198, 2006.

CAZETTA, D.A.; FORNASIERI FILHO, D.; ARF, O.; GERMANI, R. Qualidade industrial de cultivares de trigo e triticale submetidos à adubaçáo nitrogenada no sistema plantio direto. Bragantia, v.67, p.741-750, 2008.

CLAESSEN, M.E.C. (Org.) Manual de métodos de análise de solo. 2.ed. Rio de Janeiro: Embrapa CNPS, 1997. 212p. (Embrapa CNPS, Documentos, 1)

EMBRAPA. Sistema brasileiro de classificação de solos. Brasília: Embrapa, 2006. 412 p.
MALAVOLTA, E.; VITTI, G.C.; OLIVEIRA, S.A. de. Princípios, métodos e técnicas de avaliação do estado nutricional. In: MALAVOLTA, E.; VITTI, G.C.; OLIVEIRA, S.A. Avaliação do estado nutricional de plantas: princípios e aplicaçóes. 2.ed. Piracicaba: Potafos, 1997. p.115-230.

MARTINS, R.M.G.; ROSA JÚNIOR, E.J. Culturas antecessoras influenciando a cultura de milho e os atributos do solo no sistema de plantio direto. Acta Scientiarum Agronomy, v.27, p.225-232, 2005.

OKUYAMA, L.A.; FEDERIZZI, L.C.; BARBOSA NETO, J.F. Correlation and path analysis of yield and its components and plant traits in wheat. Ciência Rural, v.34, p.1701-1708, 2004.

RAIJ, B. van; CANTARELLA, H.; QUAGGIO, J.A.; FURLANI, A.M.C. (Ed.). Recomendaçôes de adubação e calagem para o Estado de São Paulo. 2.ed. Campinas: IAC, 1997. 285 p. (Boletim Técnico 100)

SANGOI, L.; BERNS, A.C.; ALMEIDA, M.L; ZANIN, C.G.; SCHWEITZER, C. Características agronômicas de cultivares de trigo em resposta à época da adubação nitrogenada de cobertura. Ciência Rural, v.37, p.1564-1570, 2007.

SANTOS, H.P.; LHAMBY, J.C.B.; SPERA, S.T.; ÁVILA, A. Efeito de práticas culturais sobre o rendimento e outras características agronômicas de trigo. Bragantia, v.65, p.669-677, 2006.

SILVA,D.A.;VITORINO,A.C.T.;SOUZA,L.C.F.;GONÇALVES, M.C.; ROSCOE, R. Culturas antecessoras e adubação nitrogenada na cultura do milho em sistema plantio direto. Revista Brasileira de Milho e Sorgo, v.5, p.75-88, 2006.

SILVA, F.A.S.E.; AZEVEDO, C.A.V. Versão do programa computacional Assistat para o sistema operacional Windows. Revista Brasileira de Produtos Agroindustriais, v.4, p.71-78, 2002.

TEIXEIRA FILHO, M.C.M; BUZETTI, S.; ALVAREZ, R.C.F.; FREITAS, J.G.; ARF, O.; SÁ, M.E. Resposta de cultivares de trigo irrigados por aspersão ao nitrogênio em cobertura na região do Cerrado. Acta Scientiarum Agronomy, v.29, p.421-425, 2007.

ZAGONEL, J.; VENÂNCIO, W.S.; KUNZ, R.P.; TANAMATI, $\mathrm{H}$. Doses de nitrogênio e densidades de plantas com e sem um regulador de crescimento afetando o trigo, cultivar OR-1. Ciência Rural, v.32, p.25-29, 2002. 